\title{
Presence of the Jonah crab Cancer borealis significantly reduces kelp consumption by the green sea urchin Strongylocentrotus droebachiensis
}

\author{
Kelly M. McKay*, Kenneth L. Heck Jr. \\ Dauphin Island Sea Lab, University of South Alabama, 101 Bienville Boulevard, Dauphin Island, Alabama 36528, USA
}

\begin{abstract}
Predators can initiate trophic cascades by reducing densities of their prey, and such density-mediated interactions are well-known in marine environments. Growing amounts of evidence suggest, however, that predator-induced modifications in prey behavior and subsequent effects on lower trophic levels, or trait-mediated interactions, may also be of fundamental importance in marine systems. In laboratory experiments we found that green sea urchins Strongylocentrotus droebachiensis, herbivores whose feeding activities can cause shifts between kelp forests and urchin barrens, significantly decreased kelp grazing rates (on average by nearly $80 \%$ ) in the presence of the echinivorous Jonah crab Cancer borealis. The Jonah crab and the green urchin co-occur across a wide geographic range and our results suggest that $C$. borealis has the potential to initiate a trophic cascade by controlling the behavior of urchins, which could have important positive effects on their kelp food resources.
\end{abstract}

KEY WORDS: Trait-mediated $\cdot$ Indirect interactions $\cdot$ Predation risk $\cdot$ Behavior $\cdot$ Herbivory

Resale or republication not permitted without written consent of the publisher

\section{INTRODUCTION}

Trophic cascades have been documented in a wide range of terrestrial and marine systems (Halaj \& Wise 2001, Borer et al. 2004, Trussell et al. 2004). The primary mechanism driving these interactions among predators, herbivores and plants has generally been believed to be density-mediated, where consumption of herbivores by predators reduces herbivore density and plant consumption, resulting in an indirect positive effect on plant biomass (Paine 1966, Carpenter et al. 1985, Schmitz et al. 2004). However, a growing body of evidence suggests that trait-mediated interactions (TMIs) may also have very substantial impacts on community dynamics through the initiation of trophic cascades (McIntosh \& Townsend 1996, Schmitz et al. 2004, Trussell et al. 2004, Preisser et al. 2005), and may be as common as density-mediated interactions (DMIs) (Werner \& Peacor 2003). Whereas DMIs are consumption-dependent, TMIs are non-lethal and occur when the behavior of a prey species is altered by the presence, or assumed presence, of a predator (Werner \& Peacor 2003). Altered prey behaviors can include reduced foraging, diet shifts and emigration (Power et al. 1985, Grabowski \& Kimbro 2005), and may often result in a reduction in grazing pressure on a primary producer, creating a trait-mediated indirect interaction (TMII) (Krivan \& Schmitz 2004, Trussell et al. 2004, Freeman 2006).

Recently, TMIs and TMIIs between marine organisms have received increased attention (see Dill et al. 2003 and Preisser et al. 2005 for reviews). For example, Trussell et al. (2004) reported a TMII between the predatory green crab Carcinus maenas, the herbivo- 
rous snail Littorina littorea and ephemeral green algae, with the presence of the green crab increasing snail emigration and releasing the algae from grazing pressure. Grabowski \& Kimbro (2005) reported that the presence of crab-eating toadfish Opsanus tau indirectly benefited clam Mercenaria mercenaria survivorship by reducing mud crab foraging, and Heithaus \& Dill (2002) reported that bottlenose dolphins Tursiops aduncus shift habitats in response to tiger shark Galeocerdo $\mathrm{Cu}$ vier presence (even though these high-risk area are also high-food areas), which may have cascading effects on bottlenose dolphin prey. In addition, Siddon \& Witman (2004) reported that presence of the lobster Homarus americanus increased survivorship of the green sea urchin Strongylocentrotus droebachiensis by modifying crab (Cancer borealis) foraging behavior, and Freeman (2006) reported that small Strongylocentrotus spp. sea urchins decrease grazing rates in the presence of the NE Pacific predatory sea star Pycnopodia helianthoides. Furthermore, a meta-analysis by Preisser et al. (2005) showed that TMIs had as strong, if not stronger, an impact on prey than direct consumption (DMIs). Although the literature has provided clear evidence of the existence of TMIs and TMIIs in marine systems, to more fully understand their commonness and importance among marine organisms, many additional trophic interactions need to be examined.

In the NW Atlantic Ocean, grazing in the rocky subtidal is dominated by the green sea urchin Strongylocentrotus droebachiensis (Scheibling 1996). The green sea urchin can profoundly alter community structure by overgrazing kelp and creating urchin barrens (Schiebling 1996, Sumi \& Sheibling 2005). This urchin is a prey item for both the predatory sunflower sea star Pycnopodia helianthoides (Freeman 2006) and, in the Atlantic Ocean, the Jonah crab Cancer borealis (Siddon \& Witman 2004). Siddon \& Witman (2004) suggested that the Jonah crab can initiate a trophic cascade by reducing urchin densities and thereby indirectly positively affect the urchins' food source (kelp), although they hypothesized that behavioral interactions may also play an important role.

In the present study, to more fully investigate the impact of TMII in the rocky subtidal of the NW Atlantic, we quantified green urchin grazing on kelp in both the presence and absence of one of its dominant predators, the Jonah crab Cancer borealis. Urchin location was monitored during trials to determine if urchins altered movement patterns when a predatory crab was present.

\section{MATERIALS AND METHODS}

To determine if non-lethal effects of the Jonah crab affected feeding rates of the green urchin on the kelp
Laminaria longicruris, we conducted laboratory experiments in the summer of 2006 at the Darling Marine Center in Walpole, Maine, USA. Siddon \& Witman (2004) reported that predation on the green sea urchin by the Jonah crab was generally observed in summer, when it may be at its annual peak. Adult green urchin individuals (test diameter 35 to $50 \mathrm{~mm}$ ) were collected from the rocky intertidal pools at Pemaquid Point and transported to the Darling Marine Center in fresh seawater. Urchins were held in a large flow-through seawater tank and starved for approximately $24 \mathrm{~h}$ before use in laboratory experiments. Large Jonah crabs (estimated carapace width 130 to $170 \mathrm{~mm}$ ) were collected from shallow waters $(<2 \mathrm{~m})$ near the Darling Marine Center either by seine or by baited lobster trap. They were starved for 24 to $48 \mathrm{~h}$ before use in experiments, were haphazardly selected for treatments and were used either 1 or 2 times.

Before use in laboratory experiments, freshly collected, similar-sized kelp pieces were spun in a salad spinner for approximately $30 \mathrm{~s}$ to remove excess water and then weighed to the nearest hundredth of a gram (weights ranged from 9.50 to $10.50 \mathrm{~g}$ ). Weighed pieces were then randomly allocated to either a control, or to 1 of 2 treatments. To maintain total immersion, each piece of kelp was weighted with a small rock. Each rock was of similar size, was movable by the urchin and therefore did not inhibit urchin feeding. Each experimental treatment contained kelp in one side of a divided $14 \mathrm{l}$ tank. A paired control was used to estimate the change in kelp wet weight when neither urchins nor crabs were present, in order to account for changes in weight due to confounding factors such as algal age, etc. In the first treatment, an urchin was allowed to feed ad libitum on a pre-weighed piece of kelp. In the second treatment, an urchin was also allowed to feed ad libitum on a pre-weighed piece of kelp with a Jonah crab present in the tank. However, the crab was separated by a plastic divider that allowed water and potential chemical cues to flow through but prevented access to the urchins. Experimental tanks were placed in a tiered flow-through water table; tanks without crabs were placed on a tier above tanks with crabs, so flow from experiments with crabs present would not contaminate predator-free treatments. Water temperature measurements were obtained from the Department of Marine Resources Boothbay Station, and average daily water temperature ranged from 17.2 to $19.8^{\circ} \mathrm{C}$ during the trials, with an average temperature of $18.6^{\circ} \mathrm{C}$. Experimental tanks were exposed to ambient light, and all experiments were run for $48 \mathrm{~h}$, which allowed sufficient time for urchin feeding.

Following the conclusion of each experiment, kelp pieces were again spun in a salad spinner for $30 \mathrm{~s}$ and re-weighed. The formula $\left[\left(H_{0} \times C_{\mathrm{f}} / C_{0}\right)-H_{\mathrm{f}}\right]$ (Cronin \& 
Hay 1996) was used to account for any kelp weight change throughout the duration of the experiment, where $H_{0}$ and $H_{\mathrm{f}}$ are the initial and final wet weights of the experimental pieces and $C_{0}$ and $C_{\mathrm{f}}$ are the initial and final wet weights of the control pieces paired to each replicate. Treatments and paired controls were each replicated 9 times.

Urchin position in the tank was also observed. The location of each urchin (categorized as on the floor, partition, far wall or side walls) was recorded at $24 \mathrm{~h}$, the middle of the trial, and at the conclusion of the trial.

\section{RESULTS}

\section{Kelp consumption}

Average paired control change of kelp wet weight during trials was $-0.037 \mathrm{~g}$, and ranged between -0.746 and $0.221 \mathrm{~g}$. When Cronin \& Hay's (1996) formula was used to correct for natural weight change of kelp during each trial, urchins in the presence of Cancer borealis consumed an average of $0.160 \mathrm{~g}$, whereas urchins in the absence of $C$. borealis consumed an average of $0.853 \mathrm{~g}$, or close to 5 times as much. Neither day nor number of times a crab was used had a significant effect on the amount of kelp consumed $(p=0.375, p=$ 0.980, respectively). Thus, in the absence of the echinivorous Jonah Crab, green sea urchins ate significantly more kelp than in the presence of the crab ( $\mathrm{p}=$ 0.040, Table 1).

\section{Urchin location}

In trials with a Jonah crab present, urchins were never found at the position closest to the predator, i.e. on the partition separating the urchin and the crab. Conversely, in trials with a Jonah crab absent, 3 urchins were located on the partition at $24 \mathrm{~h}$ and 2 at $48 \mathrm{~h}$ (Kruskal-Wallis non-parametric test: $\mathrm{p}=0.012$,
Table 1), in close proximity to the other compartment of the tank. In trials with the Jonah crab present, urchins were, with one exception, uniformly situated on side walls and the far wall (farthest from the crab) of the enclosure at both $24 \mathrm{~h}$ and $48 \mathrm{~h}$. Also, at $24 \mathrm{~h}$, 1 urchin was located on the bottom of the enclosure. In trials with the Jonah crab absent, urchin location was more evenly distributed, with urchins occupying positions on the partition, side walls, far wall and bottom. One urchin was found dead after $48 \mathrm{~h}$ in the treatment with a crab present, but this was not attributed to a lethal crab effect. Kelp consumption data from this urchin was excluded from analyses. All urchins in both treatments at $24 \mathrm{~h}$ and $48 \mathrm{~h}$ were observed to be in contact with the kelp.

\section{DISCUSSION}

The combination of results from grazing trials and location data suggests a significant TMII in the green sea urchin's response to Jonah crab presence, where urchins consumed significantly less kelp in the presence of a crab than in its absence. Cessation or a decrease in feeding is likely to be an adaptive response to predator threat; motion weakens an urchin's hold on the substrate, and active urchins are more likely to be dislodged by predators, potentially increasing the susceptibility of the vulnerable peristomal region to attack (Tegner \& Levin 1983). Cessation of feeding or a decrease in food intake, then, should decrease predation risk. Freeman (2006) also suggests that the primary response of urchins to predators is avoidance, but when avoidance is not possible, decreased or terminated feeding may be a secondary response. The Jonah crab and the green urchin co-occur in wide ranges of temperatures and habitats, and the Jonah crab has the potential to initiate a trophic cascade by controlling urchin density and/or behavior, which may have important effects on the urchins' kelp food resource (Siddon \& Witman 2004). Sumi \& Scheibling (2005) reported that when given a choice, green urchins prefer kelp (Laminaria longicruris). Reductions in kelp, a critical habitat for many fish and invertebrates (Dayton 1985, Byrnes et al. 2006), can have considerable negative consequences for animals that shelter in the kelp forests.

For a more complete understanding of this tri-trophic relationship, future studies could include field manipulations of predator and prey densities and observations in natural settings, laboratory experiments in a more real- 
istic flow regime (as used by Smee \& Weissburg 2006), the use of damaged conspecifics, and temporal variations in predation risk to test the 'predation risk allocation hypothesis' (Lima \& Bednekoff 1999).

Werner \& Peacor (2003) suggested that many ecological interactions in marine communities may be altered by behaviorally-based interactions and that TMII may be responsible for occurrences that have previously been credited to DMII. To more fully understand the roles of predation and predator avoidance in marine communities, we need to separate the effects of DMII and TMII and determine each interaction's relative importance. We agree with Schmitz et al. (2004) that it is necessary to go beyond current studies of TMII and develop an understanding of predator and prey behavioral responses, prey survivorship with predators present and absent, and to measure the indirect effect of the predator on the prey's resource.

Acknowledgements. We thank J. F. Valentine for suggestions, and M. Drymon, R. Gutierrez, C. Martin, K. Sheehan, R. Shiplett, A. Rellinger, N. Shaffer, L. Steele, and C. Steeves for their help with species collection. We also thank 4 anonymous reviewers for their invaluable comments. This research was funded by the University of South Alabama Department of Marine Science and the Dauphin Island Sea Lab.

\section{LITERATURE CITED}

Borer ET, Seabloom EW, Shurin JB, Anderson KE, Blanchette CA, Broitman B, Cooper SD, Halpern BS (2004) What determines the strength of a trophic cascade? Ecology 86: 528-537

Byrnes J, Stachowicz JJ, Hultgren KM, Hughes AR, Olyarnik SV, Thronbert CS (2006) Predator diversity strengthens trophic cascades in kelp forests by modifying herbivore behaviour. Ecol Lett 9:61-71

Carpenter SR, Kitchell JF, Hodgson JR (1985) Cascading trophic interactions and lake productivity. BioScience 35: 634-639

Cronin G, Hay ME (1996) Susceptibility to herbivores depends on recent history of both plant and animal. Ecology 77:1531-1543

Dayton PK (1985) Ecology of kelp communities. In: Johnston RF (ed) Annual review of ecology and systematics, Vol 16. Annual Reviews, Palo Alto, CA, p 215-245

Dill LW, Heithaus MR, Walters CJ (2003) Behaviorally mediated indirect interactions in marine communities and their conservation implications. Ecology 84:1151-1157

Editorial responsibility: Howard Browman, Storebø, Norway
Freeman (2006) Size-dependent trait-mediated indirect interactions among sea urchin herbivores. Behav Ecol 17: 182-187

Grabowski JH, Kimbro DL (2005) Predator-avoidance behavior extends trophic cascades to refuge habitats. Ecology 86:1312-1319

Halaj J, Wise DH (2001) Terrestrial trophic cascades: how much do they trickle? Am Nat 157:262-281

Heithaus MR, Dill LM (2002) Food availability and tiger shark predation risk influence bottlenose dolphin habitat use. Ecology 83:480-491

Krivan V, Schmitz OJ (2004) Trait and density mediated interactions in simple food webs. Oikos 107:239-250

Lima SL, Bednekoff PA (1999) Temporal variation in danger drives antipredator behavior: the predation risk allocation hypothesis. Am Nat 153:649-659

McIntosh AR, Townsend CR (1996) Interactions between fish, grazing invertebrates and algae in a New Zealand stream: a trophic cascade mediated by fish-induced changes in grazer behavior? Oecologia 108:174-181

Paine RT (1966) Food web complexity and species diversity. Am Nat 100:65-75

Power ME, Matthews WJ, Stewart AJ (1985) Grazing minnows, piscivorous bass and stream algae: dynamics of a strong interaction. Ecology 66:1448-1456

Preisser EL, Bolnick DI, Benard MF (2005) Scared to death? The effects of intimidation and consumption in predator-prey interactions. Ecology 86:501-509

Scheibling RE (1996) The role of predation in regulating sea urchin populations in eastern Canada. Oceanol Acta 19: 421-430

Schmitz OJ, Krivan V, Ovadia O (2004) Trophic cascades: the primacy of trait-mediated indirect interactions. Ecol Lett 7 : 153-163

Siddon CE, Witman JD (2004) Behavioral indirect interactions: multiple predator effects and prey switching in the rocky subtidal. Ecology 85:2938-2945

Smee DL, Weissburg MJ (2006) Hard clams (Mercenaria mercenaria) evaluate predation risk using chemical signals from predators and injured conspecifics. J Chem Ecol 32: 605-619

Sumi CBT, Scheibling RE (2005) Role of grazing by sea urchins Strongylocentrotus droebachiensis in regulating the invasive alga Codium fragile ssp. tomentosoides in Nova Scotia. Mar Ecol Prog Ser 292:203-212

Tegner MJ, Levin LA (1983) Spiny lobsters and sea urchins: analysis of a predator-prey interaction. J Exp Mar Biol Ecol 73:125-150

Trussell GC, Ewanchuk PJ, Bertness MD, Silliman BR (2004) Trophic cascades in rocky shore tide pools: distinguishing lethal and nonlethal effects. Oecologia 139:427-432

Werner EE, Peacor SD (2003) A review of trait-mediated indirect interactions in ecological communities. Ecology 84: $1083-1100$

Submitted: March 23, 2007; Accepted: September 5, 2007 Proofs received from author(s): February 27, 2008 